\title{
Sheffield

\section{A qualitative study into Egyptian patients' satisfaction with physiotherapy management of low back pain}

ALI, Nancy and MAY, Stephen

Available from Sheffield Hallam University Research Archive (SHURA) at:

http://shura.shu.ac.uk/11817/

This document is the author deposited version. You are advised to consult the publisher's version if you wish to cite from it.

\section{Published version}

ALI, Nancy and MAY, Stephen (2015). A qualitative study into Egyptian patients' satisfaction with physiotherapy management of low back pain. Physiotherapy research international, 22 (2).

Copyright and re-use policy

See http://shura.shu.ac.uk/information.html 


\section{A qualitative study into Egyptian patients' satisfaction with physiotherapy management of low back pain}

ABSTRACT Background and purpose: There is strong evidence suggesting that patient satisfaction may improve therapy outcomes independent of the treatment given. Thus the aim of this study is to explore Egyptian patients' expectations and satisfaction with physical therapy management of low back pain. Methods: A qualitative study design involving 2 focus groups and 10 semi-structured interviews; all discussions were audio recorded, transcribed verbatim and analysed using a Framework analysis approach. Results: The five final themes were about outcome of the treatment episode, the therapist characteristics, their ability to provide patient education, the service provision, and involvement in the decision-making process. Conclusion: The therapeutic encounter between patients and therapists in an episode of back care is complex and reflects the multidimensional nature of patient satisfaction. Participants had several criteria according to which they evaluated the quality of care and were able to determine when these criteria were met or not during physiotherapy.

Key words: back pain, patients, physiotherapy, satisfaction. 


\section{INTRODUCTION}

The contemporary dominant paradigm in many healthcare services is patient-centred care. Within this paradigm patient satisfaction has emerged as an important outcome in its own right. Furthermore improved satisfaction is also associated with other important outcomes, such as, greater treatment adherence, better overall outcome, and a higher quality of life (Larsson, Kreuter et al. 2010). Investigations into patient satisfaction are common, with a systematic review from 2011 reporting on 15 such studies (Hush, Cameron et al. 2011). These studies showed that satisfaction was generally very high (mean 4.44 on a one to five scale with five indicating high levels of satisfaction), and is a multidimensional phenomenon, related in particular to the interpersonal attributes of the therapist and the process of care, whereas treatment outcome was infrequently and inconsistently associated with patient satisfaction (Hush, Cameron et al. 2011).

However these studies about satisfaction were conducted predominantly in the UK, Ireland, and North America. Knowledge about satisfaction with health-care provision from non-Western countries is unknown. It is an important research objective to understand patient perspectives on healthcare from more diverse cultural backgrounds to understand if these overlap, or if they are unique and dependent on the culture. The objective of this study was to explore patients' expectations and satisfaction with physiotherapy in patients in Egypt attending for back pain using a Framework analysis approach.

\section{METHODS}

Participants were recruited from one of the largest public outpatient clinics, which is the faculty of physical therapy, Cairo University (General physiotherapy syndicate GPTS 2012), and two private physiotherapy practices in Cairo. Convenience sampling was

used to recruit patients who were receiving physiotherapy for low back pain (LBP) (Robson 2002). Participants had attended between three and ten physiotherapy sessions. 
The study's pathway was as follows. Treating clinicians invited all patients with LBP to join the study during the recruitment period with an information sheet about the study, a total of 18 out of 40 invited patients volunteered to participate. The researcher considered all volunteers as eligible and information-rich subjects according to the eligibility criteria (table 1). Table 2 shows participants' demographics and disease specific characteristics. 
Ethical approval was received from Sheffield Hallam University Health and Social Care Ethics Committee, Sheffield, UK, and from the General Physiotherapy syndicate, Cairo, Egypt. After receiving ethical approval, data collection and analysis occurred iteratively over two months in 2012, until saturation; which is the point at which further analysis did not produce new themes. To ensure saturation three more interviews were conducted to make the full number of 18 participants (Holloway and Wheeler 2002).

Data collection methods were suited to the treatment methods at the different sites. Physiotherapy in Egyptian public settings is often a shared experience, thus two focus groups of four participants each were conducted and lasted from 35-40 minutes (Agan, Koch et al. 2008). Thus each participant had adequate time for reflection and making statements and interviewer stimulation, both verbal and non-verbal, was conducted to capitalize on group interaction (Kumar 2005). Patients' experiences with physiotherapy may vary widely at private clinics, which are mostly conducted on a one-to-one basis; therefore 10 semi-structured interviews were conducted with these patients (Shenton 2004). Interviews lasted between 12 to 30 minutes, average time 18 minutes each and one interview was carried out per participant.

These data collection methods have been used widely to explore participants' opinions previously (Hush, Cameron et al. 2012; Liddle, Baxter et al. 2007; Layzell 2001). Data collection occurred at confidential meeting rooms at the recruitment sites as well-trusted places for all parties without any audience (Green and Thorogood 2009). Discussions were carried out by the researcher; audio recorded, transcribed verbatim and field notes were taken to record non-verbal behavior (Holloway 2005).

All discussions were directed by a flexible topic guide developed from pertinent literature (May 2001; McCarthy, Oldham et al. 2005; Layzell 2001; Liddle, Baxter et al. 2007) to enable similar broad issues to be covered (Kuper, Lingaard at al. 2008). The topic guide (table 3 ) comprised non-leading questions phrased in clear layman terms (Bowling 2002); not all prompts were used for all data collection, as sometimes the issues surfaced naturally through the conversation, and so that topic did not have to be 
deliberately raised. Two pilot interviews were conducted by the lead researcher using very similar prompts to those in the final interviews and focus groups, but some of the wording was changed for clarity; these interviews were not included in the final data analysis. Non-verbal probes, such as smiles and hand gestures, were used to prompt respondents' reflective thinking and encourage their active participation (Holloway and Wheeler 2002).

The role of the researcher should be considered in qualitative research. The primary researcher had worked in the hospital site previously, but made sure that no patients that she had treated were involved. She had opinions about the importance of patients' perspectives, but no a priori concepts what these might be in a different cultural setting. Furthermore data analysis was strengthened by using two independent researchers for some of the data analysis. Data collection and data analysis occurred together so that data saturation could be determined.

Framework analysis, from an interpretivism perspective (Snape and Spencer 2003), was selected to enable dynamic exploration of participants' experiences in clear, systematic and visible stages (table 4) (Ritchie and Spencer 1994). At least $50 \%$ of participants had to mention an issue for it to become a theme. The rigor of data analysis was strengthened by two independent reviewers determining themes from five transcripts and then independently coding a separate four transcripts. The lead researcher and the peer reviewer independently built an initial thematic framework from issues raised a priori from previous literature. This theoretical framework was flexibly refined with interviewing to include any new and developing themes, and resulted in the findings in table 5. If there were themes that appeared to be related to an overarching theme; these were classified as sub-themes of these main themes. The final patient transcripts were validated by the participants, in what is known as member-checking, to improve credibility.

Participants' safety, dignity and human rights were protected throughout the study according to the Declaration of Helsinki's guidelines. Detailed information sheets were 
provided and any questions were thoroughly answered. Participants' signed consents were obtained prior to data collection.

\section{Results}

The transcripts presented five themes (table 5). The quotes below are numbered according to table 2; quotes in italics were used to indicate a change in the speaker's voice (Poland 1995).

\section{Outcome}

Prior to physiotherapy, almost all participants expected physiotherapy to completely cure their back problem and prevent future episodes. Most participants considered complete recovery an important determinant of satisfaction, either immediately or over time:

'Hopefully all pain will go away and never come back this is the one thing I care about' (16)

Failure to achieve complete recovery after treatment made some participants develop negative opinions about physiotherapy:

'I had 20 sessions and it never disappeared...I'm disappointed because they just cannot help me' (2)

Some participants' expectations of therapy changed from curing to coping with LBP when the recurrent nature of LBP was explained to them:

'He said you are expecting too much because you must understand that back pain is recurrent... you must learn to cope with it, it's better than building castles in the air...he aimed for making me able to help myself at home' (1).

The majority of participants were flexible in receiving any treatment that was effective:

'My doctor told me it will be traction but my therapist said it's not that good, exercises are better for you, so I agreed after all I was happy with whatever worked' (8). However although outcome was important there were other determinants of satisfaction as seen in the additional themes.

\section{Patient education}


All participants were keen to have information and explanations about their problem. Four subthemes were distinguished which mapped the issues about which patients required information; these were the cause of back problems, patients' responsibility, the treatment plan and the prognosis.

The cause of back problems:

Nearly all participants valued a biomechanical explanation of their back problems in terms of their habits (movements and positions). This helped patients to identify their role in changing such habits to avoid the recurrence of LBP:

'It's not about patting my shoulder, he must explain the wrong movements and positions; I will not do these habits because I do not want pain again' (3).

An anatomical explanation of back pain was requested by some participants:

'I have read a few things before so I wanted to know what are the lumbar, coccygeal vertebrae made of and what is spondylosis' (17).

Patients' responsibility

All respondents appreciated advice and exercises to define their responsibility in back care. Patient education had a key role in influencing participants' mindsets, because when some participants understood the recurrent nature of LBP they embraced selfmanagement in the long-term not just for the current episode:

'It is my back, it's my responsibility to always look after it... do not slouch, exercise with the kids and always do your extensions because some pain can build-up after a long day at the kitchen' (1).

However some participants explained that the advice and exercises the therapist prescribed were not feasible with their lifestyles and depended more on the physiotherapy sessions:

'I cannot pull my knees to my chest at work can I? I sit for 8 hours to take calls; I cannot just lie down at work...so I have been coming here for mobilization for 15 sessions' (4). Some participants felt a lack of confidence in doing home exercises:

I'm still afraid of exercising at home after 12 sessions because I may hurt myself... you must train me well' (3). 
The treatment plan

An explanation of the treatment process and their role within it was wanted very commonly. The patients wanted the management plan described up front, and some justification for it:

'He must explain the plan in steps within a timeframe and the benefits of every exercise so I can do it when needed' (6).

The prognosis

Participants wanted information about their back pain in the future so that they had some understanding of the possible prognosis. This encouraged some respondents to continue exercising in the long-term and reassured others:

'Once I realized the future impacts of it, I decided to constantly exercise because it will prevent any progression' (11)

'He explained that it may get worse if I continue with my bad habits but if I watched how I sit I will be fine...that was a relief' (13)

A few respondents wanted to know about the limitations of physiotherapy in relation to any expected problems that they may need to cope with:

'Is this all he can do for me?... what should I do to keep it under control?' (10)

\section{The therapist}

There were three sub-themes that related to the therapist: a friendly and sympathetic attitude, professional competence, and gender. Several characteristics were noted by a range of patients: listening, patience, genuine care and empathy:

'She said you are like my mother, she listens and understands and sympathizes with my situation, she is keen on me, she holds my hand, but he yells and I wonder why is he condescending? (14).

Regarding the therapists' professional competence; participants perceived the 'clever therapist' to have a range of skills for example knowledge, thoroughness, precision, confidence, effectiveness and safety: 
'The clever therapist fixes your back and won't make it worse because precision is important... he is a good reader, sure of himself and convincing' (18).

'The clever therapist is skillful, doesn't miss a point and can make you better' (12) Respondents felt that morals, dedication and passion for physiotherapy are the most important qualities that therapists needed to convey through their attitude and performance to gain participants' trust and respect:

'She has personal values...it's not about money she loves her job, it shows when she talks and does different things to help me...she gained my trust and respect...for others it's a routine' (10).

Most of the respondents felt more comfortable dealing with a therapist of the same gender. However working with an expert from the opposite gender was sometimes favored over less experienced therapists of the same gender:

'Because of my religious believes I feel comfortable with a girl like me, but she wasn't qualified for manipulations so I let him do it because he was polite' (15)

\section{Service provision}

In the public and private sectors; respondents stressed the importance of the organization delivering the care, such as, convenient location and hours, easy bookings for appointments, short waiting times, and note keeping. Also, consistently working with the same therapist and being reevaluated by experienced therapists were important. Lower satisfaction was related to poor standards of treatment facilities including hygiene, privacy, noise and the lack of up-to-date equipment:

'They keep me waiting, lose my notes and I want to work with the same person... the senior must check on me...the clinic is noisy...the sheets are sometimes not clean and the ultrasound machines are too old' (8).

Those who had used both sectors thought that the public sector was better quality than the private because of effectiveness and cost.

\section{Decision making}

Most respondents preferred to delegate decision-making to therapists because they had faith in the experts' opinion to prevent them from making wrong decisions: 
'Do as you are told, obey the expert... he knows better, I don't like therapists who give me options even when they explain...I trust you so you take care of me even if it means more sessions... what if I do the wrong thing' (12).

However some respondents were encouraged to participate in planning their treatment when the therapists explained that participants' input can help to customize the therapy to suit their needs:

'I thought it was best if he decides but we had this dialogue and he convinced me...I chose to do it in standing because I work on site...I like doing my exercises on site and my back hurts less often; he is really skilled...I'm on top of it and decided to look-after myself after 3 sessions' (7).

\section{Discussion}

This is a qualitative study that used focus groups and semi-structured interviews to explore Egyptian patients' satisfaction with physiotherapy for LBP. The key finding from this study is that patient satisfaction is multifactorial because respondents evaluated care according to several criteria. Although outcome was a component of satisfaction this was not just about recovery, but could include the development of coping strategies and patient education. Other components of satisfaction included the characteristics of the therapist, namely their manner and their professional competence; the provision of information, namely about the problem, the treatment plan, what they could do to help themselves, and prognosis; service provision, and decision-making. Of interest is the finding that the components of satisfaction were the same in both private and public sectors.

Very similar dimensions were identified in previous research relating to outcome (May 2001; Verbeek, Sengers et al. 2004; MacDonald, Cox et al. 2002), the therapists' personal and professional manner (May 2001; Verbeek, Sengers et al. 2004; MacDonald, Cox et al. 2002), effectiveness (McCarthy, Oldham et al. 2005; MacDonald, Cox et al. 2002), information (May 2001; McCarthy, Oldham et al. 2005; Verbeek, Sengers et al. 2004; MacDonald, Cox et al. 2002), decision-making (May 2001; Verbeek, Sengers et al. 2004) and the organization of services (May 2001; McCarthy, 
Oldham et al. 2005; MacDonald, Cox et al. 2002). Other studies into satisfaction looked at different care-providers, and were not focused only on physiotherapists (Layzell 2001; Law 1995; McKinnon 2000). Many of the components of satisfaction were very similar to previous studies, in which data had been gathered in Europe or North America, such as outcome, patient education, the manner of the therapist, service provision, and decision-making. Whereas being treated by a clinician of the same gender was a new dimension in this study. From the participants viewpoint this is probably related to the conservative traditions of Middle Eastern societies that frown on casual relationships between opposite genders outside of the family environment (Kulwicki 2008).

The study revealed a dichotomy relating to self-management. The participants both valued information about self-management, but also tended to favor decision-making by the therapist rather than themselves. Patient education was a major component of this and previous studies about satisfaction with physiotherapy and healthcare in general. It is here that the dichotomy occurs, as the patients have gone to a healthcare expert in order to seek advice and probably treatment. However rather than being seen as a miss-match between patient expectations and healthcare provision, maybe selfmanagement should be seen in the light of the concept of therapeutic alliance (Lorig 2002), in which both healthcare professionals and patients have a shared role in surmounting a problem. This dual role of the therapist and the patients clearly illustrates this therapeutic alliance, and clearly is at the heart of patient-centered care, but also demonstrates that this can be complex in nature at times and probably relates to the multifactorial nature of patient satisfaction (Lorig 2002; May 2010).

It has been suggested that the conceptual framework that informs patient satisfaction is related to patient expectations and needs, but that it is a very complex construct (Hills and Kitchen 2007a). In this framework satisfaction arises when patients' biopsychosocial needs are met, and when their expectations of the therapeutic intervention have been fulfilled (Hills and Kitchen 2007a). Specifically expectations relate to the therapeutic encounter and the clinical outcome (Hills and Kitchen 2007b). 
The therapeutic encounter comprises the therapist, communication and organisational issues; whilst the clinical outcome focuses on symptomatic improvement (Hills and Kitchen 2007b). Obviously there is close interplay between these variables, but interestingly despite different cultural settings very similar issues arose in the present study.

There are numerous barriers and facilitators to the process of providing information and encouraging self-management, as this study makes clear. Patients do want information to facilitate self-management, but at the same time there is a tendency to delegate decision-making to the healthcare professional. This in some ways fits in with the concept of health locus of control, in which those with an external health locus of control are more likely to seek health professional help, whereas those with an internal health locus of control are less likely (May 2010). Health locus of control, amongst other variables, can affect health behaviors, but there is limited evidence that it affects healthcare seeking, though this would logical (Luszcczyska and Schwarzer 2005). In other words, patients' needs for self-management advice maybe on a continuum, with a range of needs between patients. The concept of a therapeutic alliance maybe most relevant to this debate, as this depicts equalized roles for professional and patient. The ambivalence of patients seeking help, but also wanting information on self-management has arisen in previous studies, but has not been highlighted before (Hush, Cameron et al. 2011). So it is not clear that this is a cultural issue.

\section{Limitations}

As with all qualitative studies this research has the potential for bias, especially in regard of sample and recruitment bias, and analysis bias. To increase transferability; data collection was done in different sites, one public and two private settings to add diversity, but different cities were not included (Holloway and Wheeler 2002). However the public clinic selected is attended by patients from many cities (GPTS website 2012). Participants who joined the study represented $45 \%$ of the total number of patients invited; this may suggest volunteer bias, but this is mandatory in ethical research (Kumar 2005); and those not wishing to participate did not have to give a reason. The 
sample provided equal numbers from both genders, stages of the conditions (acute and chronic), stages of the rehabilitation process, and a large age range, and data was collected from a number of sites, which may suggest adequate sampling of balanced perspectives. The patients involved had had a range of treatment sessions, between three and ten, but the study did not look at whether their stage in rehabilitation affected satisfaction. A previous study found that acute, older and female patients tended to be more satisfied (Hills and Kitchen 2007), and it is suggested that this was related to variable patient expectations (Hush, Cameron et al. 2011). However the present study did not make a distinction between these groups of patients, though all were included.

Independent analysis was conducted by the lead researcher and a colleague with experience in qualitative research to ensure that the generated themes were comprehensive and representative of the collected data, which increases quality control and is more likely to ensure rigor in the data analysis process (Hancock, Windridge et al. 2007). Also, positive and negative quotations about the presence and absence of an aspect of care respectively; reinforced credibility of the components of patient satisfaction (Silverman 2000). To endorse dependability; no patient who was treated by the researcher was involved in the study which allowed participants to freely offer negative feedback (Lacey and Luff 2009). A systematic and transparent audit trail was kept as a site file which can aid dependability and increase confirmability.

\section{Implications}

There are a number of research and educational implications arising from this study. Firstly developing good rapport with patients with chronic conditions like LBP can create a good opportunity to convince patients to adopt long-term self-management strategies, which can increase patients' confidence, independence and decrease work absence due to LBP (Adamson, Bland al. 2008). Secondly, patients' develop greater autonomy and may need less physiotherapy sessions thereby decreasing the economic burden of LBP, given that Egyptians pay $51 \%$ of the healthcare budget out of their own pockets (Rannan-Eliya, Nada et al. 1998). Thirdly the concepts of realistic expectation, and importance of self-management skills need to be emphasized in Egyptian therapists' 
initial training to build-up their communication and negotiation skills (Bennett-Levy 2006). Fourthly, further research is needed to fully explore Egyptians' beliefs and attitudes about LBP and to identify if there are more areas where patient and public awareness is needed.

Additionally it would also be important to explore Egyptian therapists' perspectives on patient involvement and satisfaction to determine if the management used addresses the patients' needs identified by this study (Matthias, Parpart et al. 2010). Accordingly, physiotherapists can establish their accountability as credible professionals who are committed to 'best practice' by reflecting on clinical reasoning to adopt a more evidence-based practice which values patients' contribution and targets their individual needs. Finally it is interesting to note the confirmation of key determinants of satisfaction in a different and novel context, and the apparent desire by patients to be led by therapists.

\section{Conclusion}

The study provides evidence that the therapeutic encounter between patients and therapists in an episode of back care reflects the multidimensional nature of patient satisfaction. Key issues were the outcome of an episode of care, patient education, the attributes of the therapist, the structure of the service and decision-making. Patients appeared to want advice, and therapist-led treatment from an informed and accessible clinician. Patients consider their satisfaction with these dimensions as integral measures in evaluating back care. Egyptian therapists need to consider if their care meets these aspects of patients' expectations, and to consider the use of patient satisfaction as a relevant and appropriate outcome measure.

\section{References}

Adamson S, Bland J, Hay E, Johnson R, Jones G, Kitchener H, Moffett J, MacFarlane G, Macpherson H, Mclean S. Patients' preferences within randomised trials: Systematic review and patient level meta-analysis. British Medical Journal 2008337 1136-1864. 
Agan J, Koch L, Rumrill P. The use of focus groups in rehabilitation research. Work 200831 259-264.

Bennett-Levy J. Therapist skills: a cognitive model of their acquisition and refinement. Behavioral and Cognitive Psychotherapy 200634 57-78.

Bowling A. Research Methods in Health. Open University Press Philadelphia 2002.

General Physiotherapy syndicate (GPTS), Cairo University, Cairo 2012.

Green J, Thorogood N. Qualitative Methods for Health Research. Sage London 2009.

Hancock B, Windridge K, Ockleford E. An Introduction to Qualitative Research. Trent Research and Development Support Unit London 2007.

Hills R, Kitchen S. Toward a theory of patient satisfaction with physiotherapy: exploring the concept of satisfaction. Physiotherapy Theory and Practice 2007a 23 243-254.

Hills R, Kitchen S. Development of a model of patient satisfaction with physiotherapy. Physiotherapy Theory and Practice 2007b 23 255-271.

Holloway I. Qualitative Research in Health Care. Open University Press Berkshire 2005. Holloway I, Wheeler S. Qualitative Research in Nursing. Wiley-Blackwell Oxford 2002.

Hush JM, Cameron K, Mackey M. Patient satisfaction with musculoskeletal physical therapy care: A systematic review. Physical Therapy 2011 91 25-36.

Kumar R. Research Methodology: A Step-by-Step Guide for Beginners. Sage Publications Ltd Newbury Park 2005.

Kulwicki A. People of Arab heritage. In Purnell L, Paulanka B (Eds) Transcultural Health Care: A Culturally Competent Approach. Davis Company Philadelphia 2008.

Kuper A, Lingard L, Levinson W. Critically appraising qualitative research. British Medical Journal 2008337 687-692.

Lacey S, Luff D. Qualitative Data Analysis. The NHS National Institute for Health Research London 2009.

Larsson MEH, Kreuter M, Nordholm L. Is patient responsibility for managing musculoskeletal disorders related to self-reported better outcome of physiotherapy treatment? Physiotherapy Theory and Practice 201026 308-317.

Law M. Client-centred practice: What does it mean and does it make a difference? Canadian Journal of Occupational Therapy 199562 250-257. 
Layzell M. Back pain management: A patient satisfaction study of services. British Journal of Nursing 200110 800-807.

Liddle SD, Baxter GD, Gracey JH. Chronic low back pain: Patients' experiences, opinions and expectations for clinical management. Disability \& Rehabilitation 200729 1899-1909.

Lorig K. Partnership between expert patients and physicians. Lancet 2002359 814-815. Luszcczyska A, Schwarzer R. Multidimensional health locus of control: comments on the construct and its measurement. Journal of Health Psychology 200510 633-642. Macdonald CA, Cox PD, Bartlet DJ. Productivity and client satisfaction: A comparison between physical therapists and student-therapist pairs. Physiotherapy Canada 200254 92-101.

Matthias M, Parpart A, Nyland K, Huffman M, Stubbs D, Sargent D, Bair M. The patient-provider relationship in chronic pain care: Providers' perspectives. Pain Medicine 201011 1688-1697.

May S J. Patient satisfaction with management of back pain. Parts 1 and 2 . Physiotherapy 200187 4-20.

May S. Self-management of chronic low back pain and osteoarthritis. Nature Reviews Rheumatology 20106 199-209.

McCarthy CJ, Oldham JA, Sephton R. Expectations and satisfaction of patients with low back pain attending a multidisciplinary rehabilitation service. Physiotherapy Research International 200510 23-31.

McKinnon AL. Client values and satisfaction with occupational therapy. Scandinavian Journal of Occupational Therapy 20007 99-106.

Poland PD. Transcription quality as an aspect of rigor in qualitative research. Qualitative Inquiry 19951 290-310.

Rannan-Eliya R, Nada K, Kamal A, Ali A. Egypt National Health Accounts 1994/95. Ministry of Health and Population Cairo 1997.

Ritchie J, Spencer L. Qualitative data analysis for applied policy research. In Bryman A, Burgess RG (Eds) Analyzing Qualitative Data. Routledge London 1994.

Robson C. Real World Research: A resource for social scientists and practitionerresearchers. Wiley-Blackwell Oxford 2002. 
Shenton AK. Strategies for ensuring trustworthiness in qualitative research projects. Education for Information 200422 63-76.

Silverman D. Doing Qualitative Research: a Practical Handbook. Sage London 2000.

Snape D, Spencer L. The foundations of qualitative research. In Ritchie J, Lewis J (Eds)

Qualitative Research Practice. A Guide for Social Science Students and Researchers. Sage Publications London 2003.

Verbeek J, Sengers MJ, Riemens L, Haafkens J. Patient expectations of treatment for back pain: A systematic review of qualitative and quantitative studies. Spine 200429 2309-2318.

\section{Table 1: Eligibility criteria}

\begin{tabular}{|c|c|}
\hline Inclusion criteria & Exclusion criteria \\
\hline $\begin{array}{l}\text { Egyptian participants with non-specific low back } \\
\text { pain (LBP) of any duration. } \\
\text { The case definition of LBP used in this study: } \\
\text { Topography: any symptoms in the area between } \\
\text { the } 12^{\text {th }} \text { rib and the gluteal folds with or without } \\
\text { leg symptoms. } \\
\text { Temporality: } \\
\text { Acute pain is of a duration }=\text { or }<3 \text { weeks } \\
\text { Sub-acute pain is of a duration between } 3 \\
\text { weeks and } 3 \text { months }\end{array}$ & $\begin{array}{l}\text { Patients with LBP who require urgent } \\
\text { physiotherapy or are medically unstable, to avoid } \\
\text { interrupting their management. }\end{array}$ \\
\hline
\end{tabular}




\begin{tabular}{|l|l|}
\hline chronic pain is of a duration $=$ or $>3$ months & \\
\hline $\begin{array}{l}\text { Patients who have previously received or are } \\
\text { receiving physiotherapy for low back in either } \\
\text { public hospitals or private clinics }\end{array}$ & $\begin{array}{l}\text { Unable to speak Arabic or English to suit the } \\
\text { principle researcher. }\end{array}$ \\
\hline $\begin{array}{l}\text { Those who willingly volunteer to join the } \\
\text { research. }\end{array}$ & $\begin{array}{l}\text { Those who are unwilling or unable to provide } \\
\text { signed informed consent or do not wish to } \\
\text { discuss their views. }\end{array}$ \\
\hline $\begin{array}{l}\text { Participants who are } 18 \text { years old or above, to } \\
\text { ensure their ability to provide an informed } \\
\text { consent. } \\
\begin{array}{l}\text { Also because the nature of LBP and } \\
\text { satisfaction criteria may differ in a population } \\
\text { younger than } 18 \text { years old. }\end{array}\end{array}$ \\
\hline
\end{tabular}


Table 2: Participants' details

\begin{tabular}{|c|c|c|c|c|c|c|c|}
\hline Participant & Gender & Age & Settings & History of the condition & Education & Occupation & $\begin{array}{c}\text { Previous } \\
\text { physiotherapy }\end{array}$ \\
\hline 1 & $\mathrm{~F}$ & 32 & Private & Acute $<3$ weeks & Higher education & Housewife & Y \\
\hline 2 & M & 81 & Private & Chronic $>3$ years & Higher education & Retired & $\mathrm{Y}+$ \\
\hline 3 & $\mathrm{~F}$ & 24 & Private & Chronic> 12 years & Higher education & $\begin{array}{c}\text { Call center } \\
\text { agent } \\
\text { On sick leave }\end{array}$ & $\mathrm{Y}$ \\
\hline 4 & M & 25 & Private & $\begin{array}{l}\text { Acute }<3 \text { weeks, forced to } \\
\text { take a sick leave from work }\end{array}$ & Higher education & $\begin{array}{c}\text { Call center } \\
\text { agent } \\
\text { On sick leave }\end{array}$ & $\mathrm{Y}$ \\
\hline 5 & M & 48 & Private & $\begin{array}{l}\text { Acute }<3 \text { weeks, motor } \\
\text { weakness of ankle dorsiflexors } \\
\text { and hip abductors }\end{array}$ & Higher education & Sales agent & $\mathrm{Y}$ \\
\hline 6 & M & 25 & Private & Acute $<3$ weeks & Higher education & Bank manager & $\mathrm{Y}$ \\
\hline 7 & M & 56 & Private & Chronic> 20 years & Higher education & Architect & $\mathrm{Y}$ \\
\hline 8 & $\mathrm{~F}$ & 48 & Private & Chronic> several episodes & Higher education & Housewife & $\bar{Y}$ \\
\hline 9 & $\mathrm{~F}$ & 29 & Private & Chronic> 3 months & Higher education & Physician & $\mathrm{Y}+$ \\
\hline 10 & $\mathrm{~F}$ & 27 & Private & Chronic> 3 years, scoliosis & Higher education & Housewife & $\mathrm{Y}+$ \\
\hline 11 & M & 65 & Public & Chronic, several episodes & Higher education & Retired & $\mathrm{Y}$ \\
\hline 12 & M & 48 & Public & Chronic, several episodes & Higher education & Teacher & $\mathrm{Y}$ \\
\hline 13 & M & 39 & Public & Acute $>3$ weeks & Higher education & $\begin{array}{c}\text { Social } \\
\text { researcher }\end{array}$ & $\mathrm{Y}$ \\
\hline 14 & $\mathrm{~F}$ & 50 & Public & Acute & Secondary education & Housewife & $\mathrm{Y}$ \\
\hline
\end{tabular}




\begin{tabular}{|c|c|c|c|l|c|c|c|}
\hline 15 & $\mathrm{~F}$ & 40 & Public & Chronis, several episodes & Secondary education & Housewife & $\mathrm{Y}$ \\
\hline 16 & $\mathrm{~F}$ & 40 & Public & Acute, other pathologies & Higher education & Accountant & $\mathrm{Y}$ \\
\hline 17 & $\mathrm{~F}$ & 27 & Public & Acute, other pathologies & Secondary education & Housewife & $\mathrm{Y}$ \\
\hline 18 & $\mathrm{M}$ & 19 & Public & Acute, scoliosis & Higher education & Student & $\mathrm{Y}$ \\
\hline $\begin{array}{l}\text { Key: Y=previous physiotherapy, Y+= several physiotherapy episodes (Generally the treatment consisted of: ultrasound, transcutaneous electrical } \\
\text { nerve stimulation, hot packs, abdominal and back muscle strengthening, hamstrings and prififormis stretching. Manual techniques included lumbar } \\
\text { mobilization and manipulation while soft tissue techniques included myofascial release and massage techniques). }\end{array}$
\end{tabular}

\section{Table 3: Topic guide (in any order)}

Issues generated from pertinent literature

Expectations:

\section{Questions refined with piloting}

Before receiving any physiotherapy, what did you think

the treatment will consist of?

Where did you get these ideas from?

Were your expectations met? Do you think the treatment is effective or are you getting better?

Information and education:
Was your problem fully and easily explained?

Were you given enough information about your condition?

Were all of your questions answered to your content?

Was an explanation given on how a particular treatment worked? 


\begin{tabular}{|l|l|}
\hline & $\begin{array}{l}\text { Was information/advices provided to help you manage } \\
\text { your problem by yourself? }\end{array}$ \\
\hline Interaction: & $\begin{array}{l}\text { Do you prefer working with a therapist of the same } \\
\text { gender? } \\
\text { Was the physiotherapist understanding and helpful? } \\
\text { Do you prefer to be actively involved with the therapist } \\
\text { in choosing what treatment you get or do you prefer to } \\
\text { leave it all to the physiotherapist? }\end{array}$ \\
\hline Practicalities: & $\begin{array}{l}\text { What do you think about the cost of physiotherapy } \\
\text { sessions? } \\
\text { Do you have any comments on the sessions' time? } \\
\text { Do you have any comments on the available facilities? }\end{array}$ \\
\hline Overall satisfaction: & \begin{tabular}{l} 
Do you have any other points? \\
\hline
\end{tabular} \\
\hline
\end{tabular}

\section{Table 4: The stages of framework analysis (Ritchie, Spencer 1994)}

\section{Stage Performed analysis}

\begin{tabular}{l|l} 
Familiarization & listening to recordings, verbatim transcribing, reading field notes
\end{tabular} 


\begin{tabular}{|l|l|}
\hline & $\begin{array}{l}\text { and transcripts several times to enable prolonged raw data } \\
\text { immersion }\end{array}$ \\
\hline $\begin{array}{l}\text { Identification of a } \\
\text { framework }\end{array}$ & $\begin{array}{l}\text { The lead researcher and the peer reviewer independently built an } \\
\text { initial thematic framework from issues raised a priori from } \\
\text { previous literature. This theoretical framework was flexibly refined } \\
\text { with additional themes from the first five interviews. }\end{array}$ \\
\hline Indexing & $\begin{array}{l}\text { The researcher and the peer reviewer blindly annotated four } \\
\text { transcripts using color codes according to the developed thematic } \\
\text { framework. Once the framework was finalized it was set to all raw } \\
\text { data, followed by a discussion to reach a consensus on theme } \\
\text { definitions. }\end{array}$ \\
\hline Charting & $\begin{array}{l}\text { Cross section comparisons between transcripts were done to } \\
\text { group repeated codes, and then headings from the framework } \\
\text { were sketched into charts. }\end{array}$ \\
\hline Mapping & $\begin{array}{l}\text { Visual aids were used to search for explanations and } \\
\text { relationships between themes across all transcripts. }\end{array}$ \\
\hline
\end{tabular}

\section{Table 5: Key themes generated from the transcripts}




\begin{tabular}{|c|c|c|}
\hline Final themes & Definitions & Sub-themes \\
\hline Outcome & $\begin{array}{l}\text { Patients expectations about the } \\
\text { outcomes of physiotherapy and } \\
\text { the means of achieving such } \\
\text { outcomes }\end{array}$ & $\begin{array}{l}\text { High expectations of complete } \\
\text { recovery before starting } \\
\text { physiotherapy. } \\
\text { After physiotherapy some } \\
\text { participants perceived that the } \\
\text { outcome of physiotherapy was } \\
\text { to develop coping strategies. } \\
\text { Participants appreciated any } \\
\text { effective therapy which can } \\
\text { achieve the desired outcome. }\end{array}$ \\
\hline Patient education & $\begin{array}{l}\text { The therapists' role in explaining } \\
\text { and teaching }\end{array}$ & $\begin{array}{l}\text { The cause of back problems } \\
\text { Patients' responsibility in back } \\
\text { care } \\
\text { The treatment plan } \\
\text { The prognosis }\end{array}$ \\
\hline The therapist & $\begin{array}{l}\text { Characteristics of the } \\
\text { physiotherapists that patients' } \\
\text { desired or criticized }\end{array}$ & $\begin{array}{l}\text { Attitude: friendly, sympathetic, } \\
\text { respectful, good listener and } \\
\text { caring. } \\
\text { Competence: skillful, thorough, } \\
\text { precise and has good } \\
\text { knowledge. } \\
\text { Preferably of the same gender }\end{array}$ \\
\hline Service provision & Issues related to the provision of & Organization \\
\hline
\end{tabular}




\begin{tabular}{|l|l|l|}
\hline & physiotherapy services & $\begin{array}{l}\text { Standard of the premises } \\
\text { Having enough time } \\
\text { Consistency of care } \\
\text { Value for money }\end{array}$ \\
\hline Decision making & $\begin{array}{l}\text { Patients' preferences around } \\
\text { participation in treatment } \\
\text { selection and clinical decision } \\
\text { making. }\end{array}$ & $\begin{array}{l}\text { Do not want to participate } \\
\text { Wanted to participate }\end{array}$ \\
\hline
\end{tabular}

